\title{
Risk factors and mediating pathways of loneliness and social support in community-dwelling older adults
}

Rebecca I.B. Schnittger, Joseph Wherton, David Prendergast \& Brian A. Lawlor

To cite this article: Rebecca I.B. Schnittger, Joseph Wherton, David Prendergast \& Brian A. Lawlor (2012) Risk factors and mediating pathways of loneliness and social support in communitydwelling older adults, Aging \& Mental Health, 16:3, 335-346, DOI: 10.1080/13607863.2011.629092

To link to this article: https://doi.org/10.1080/13607863.2011.629092

曲 Published online: 30 Nov 2011.

Submit your article to this journal $\pi$

Џll Article views: 1266

Citing articles: 33 View citing articles 


\title{
Risk factors and mediating pathways of loneliness and social support in community-dwelling older adults
}

\author{
Rebecca I.B. Schnittger ${ }^{\text {ab* }}$, Joseph Wherton ${ }^{\text {ab }}$, David Prendergast ${ }^{\mathrm{c}}$ and Brian A. Lawlor ${ }^{\text {ad }}$ \\ ${ }^{a}$ Technology Research for Independent Living (TRIL) Centre, St. James's Hospital, Dublin, Ireland; ${ }^{b}$ Trinity \\ College Institute of Neuroscience (TCIN), Trinity College, Dublin, Ireland; ${ }^{c}$ Health Research \& Innovation, \\ Intel Labs, Leixlip, Co. Kildare, Ireland; 'Department of Psychiatry, Trinity College, Dublin, Ireland
}

(Received 30 March 2011; final version received 29 August 2011)

\begin{abstract}
Objectives: To develop biopsychosocial models of loneliness and social support thereby identifying their key risk factors in an Irish sample of community-dwelling older adults. Additionally, to investigate indirect effects of social support on loneliness through mediating risk factors.

Methods: A total of 579 participants (400 females; 179 males) were given a battery of biopsychosocial assessments with the primary measures being the De Jong Gierveld Loneliness Scale and the Lubben Social Network Scale along with a broad range of secondary measures.

Analysis: Bivariate correlation analyses identified items to be included in separate psychosocial, cognitive, biological and demographic multiple regression analyses. The resulting model items were then entered into further multiple regression analyses to obtain overall models. Following this, bootstrapping mediation analyses was conducted to examine indirect effects of social support on the subtypes (emotional and social) of loneliness. Results: The overall model for (1) emotional loneliness included depression, neuroticism, perceived stress, living alone and accommodation type, (2) social loneliness included neuroticism, perceived stress, animal naming and number of grandchildren and (3) social support included extraversion, executive functioning (Trail Making Test B-time), history of falls, age and whether the participant drives or not. Social support influenced emotional loneliness predominantly through indirect means, while its effect on social loneliness was more direct.

Conclusions: These results characterise the biopsychosocial risk factors of emotional loneliness, social loneliness and social support and identify key pathways by which social support influences emotional and social loneliness. These findings highlight issues with the potential for consideration in the development of targeted interventions.
\end{abstract}

Keywords: mental health measures; loss/bereavement/life events; physical health measures; psychological and social aspects; personality

\section{Introduction}

Loneliness is a pervasive issue among the elderly with strong links to social support, both mental and physical health as well as cognition. When examining loneliness in older adults, it is important to consider it as a subjective experience distinct from social isolation and social support. Cognitive theories of loneliness suggest it arises through a mismatch of the actual quantity and quality of social networks and the desired levels (de Jong Gierveld, van Tilburg, \& Dykstra, 2006; Perlman \& Peplau, 1981). For many older adults their social groups will have decreased in size due to their own illness or frailty, the illness or frailty of a loved one for whom they are a carer, or the illness, frailty or death of individuals in their own social groups. However, not all individuals who are socially isolated or who have small social support networks are lonely. Additionally, it is possible to feel lonely even when socially integrated and possessing large support networks. Significantly, according to the cognitive perspective (Perlman \& Peplau, 1981), a discrepancy between actual and desired social relations is not necessarily sufficient for feelings of loneliness to occur but is itself modulated by cognitive processes such as causal attributions, social comparisons and perceived control. Regardless, it is apparent that there is a strong relationship between social support networks and loneliness (Cacioppo, Fowler, \& Christakis, 2009; Golden et al., 2009; Stokes, 1985).

When considering the different pathways to loneliness, it is particularly vital to distinguish between different forms of loneliness. Weiss (1973) identified two primary forms of loneliness: emotional loneliness, which involves the lack or loss of a close attachment relationship; and social loneliness, which stems from the lack of a satisfying and engaging social network. Making a distinction between emotional loneliness and social loneliness can be beneficial, when considering the evolution of loneliness within individuals (van Baarsen, Snijders, Smit, \& van Duijn, 2001) and also in the development of interventions.

In an investigation into loneliness in Ireland, Drennan et al. (2008) examined the sociodemographic predictors of family, romantic and social loneliness. Family and romantic loneliness were included under the general heading of emotional loneliness, and the risk factors were identified as; being widowed, divorced or separated as well as living in a rural setting, gender, 
infrequent access to children and relatives and caring for a spouse or relative at home. In comparison, risk factors for social loneliness included living in a rural area, greater age, poorer health and lack of contact with a friend. The evidence is contradictory regarding the specific effect of contact with children on loneliness; however, contact with grandchildren has consistently been noted as a significant risk factor for loneliness (Heylen, 2010; Routasalo, Savikko, Tilvis, Strandberg, \& Pitkälä Kaisu, 2006; Savikko, 2008). Perceived social support levels have been shown not to fluctuate greatly over the life span (Gurung, Taylor, \& Seeman, 2003), instead it is the type of support which may change. Lansford, Sherman and Antonucci (1998) suggest smaller close-knit groups become predominant as individuals age.

The links between mental health and loneliness in older adults are well established. Depression in particular has been found to have a strong association with loneliness (Barg et al., 2006; Cacioppo, Hughes, Waite, Hawkley, \& Thisted, 2006; Savikko, 2008; Stek et al., 2005); although emotional loneliness and social loneliness are seldom considered separately. Similarly, Russell and Cutrona (1991) identified initial levels of social support as a predictor of levels of depression 1 year later. The relationship between loneliness and anxiety is less clear although evidence of such an association does exist. Fees, Martin and Poon (1999) found the effects of anxiety to be mediated by perceived loneliness in older adults. Similarly, in a study of the oldest old and their adult children, individuals with anxious personalities and who were less extraverted were found to be more likely to be lonely (Long \& Martin, 2000). While a strong association between neuroticism and loneliness has previously been identified, research in this area has been primarily conducted on college students (Stokes, 1985) and adolescents (Lasgaard \& Elklit, 2009) and therefore cannot be fully generalised to older adult populations.

Associations between cognition, loneliness and social support have been reported, although the precise nature of this relationship is in need of further clarification. Both loneliness (Tilvis et al., 2004; Wilson et al., 2007) and social network (Fratiglioni, Wang, Ericsson, Maytan, \& Winblad, 2000) have been identified as risk factors for dementia. More generally, in a 10-year longitudinal follow-up of older adults, Tilvis et al. (2004) identified loneliness as an independent predictor of cognitive decline. More recently, Wilson et al. (2007) examined loneliness as a risk factor for developing Alzheimer disease in a longitudinal follow-up of 823 older adults. Loneliness was associated with poorer cognitive performance at baseline and with faster cognitive decline. Additionally, the risk of Alzheimer disease was more than doubled in lonely individuals compared to those who were not lonely. With regard to social network, Fratiglioni et al. (2000) found a $60 \%$ increased risk of dementia in individuals with poor or limited social network in a follow-up of individuals who had good cognition at baseline. With relation to semantic fluency, Gilmour (2011) has recently reported a relationship between the animal naming task and general loneliness, although this relationship did not persist following multivariate analysis.

The specific nature of the relationship between health and loneliness, while not well defined, is well documented. Loneliness has been associated with poor subjective health (Savikko, 2008), hearing impairments and lung disease (Kramer, Kapteyn, Kuik, \& Deeg, 2002; Penninx et al., 1999), an increased risk of heart conditions and disrupted autonomic regulation (Hawkley, Masi, Berry, \& Cacioppo, 2006; Sorkin, Rook, \& Lu, 2002; Steptoe, Owen, Kunz-Ebrecht, \& Brydon, 2004), obesity (Lauder, Mummery, Jones, \& Caperchione, 2006), osteoarthritis and rheumatoid arthritis (Penninx et al., 1999), poorer sleep quality and larger age-related blood pressure increases (Cacioppo et al., 2002).With regard to physical illness, functional incapacitation may influence an individuals' ability to maintain pre-existing, and develop new, social relationships and may also affect their desire to engage in outside activities due to either an embarrassment over their condition or a fear of injuring themselves. This limiting of social contacts may result in a diminishing social support and/or to feelings of loneliness developing (Penninx et al. 1999). Mortality is another issue affected by loneliness. Patterson and Veenstra (2010) identified significantly higher chances of all-cause mortality among individuals who report feeling lonely compared to those who report never feeling lonely. In particular, mortality rates from cardiovascular diseases other than ischemic disease were more than doubled for individuals reporting themselves as often being lonely; this is even when age and gender were controlled for. Patterson and Veenstra suggest that this association between loneliness and mortality may be mediated to some extent by physical activity and depression although further research is needed to elucidate this.

The primary aim of this study is to identify the biopsychosocial and cognitive risk factors of emotional loneliness, social loneliness and social support. An initial broad approach will be taken including a wide array of psychosocial, cognitive, biological and demographic variables. This initial array will be screened for inclusion in follow-up analyses, which will allow for very specific models of loneliness and social support to be created. A secondary aim is to examine mediating effects in the relationship between social support and outcomes of emotional and social loneliness. By investigating direct factors affecting loneliness and social support, and also mediating factors in the relationship between loneliness and social support, it is hoped that this will aid in identifying those at risk of developing loneliness or low levels of social support and also in determining how social support impacts on loneliness. This may help explain why certain individuals are lonely or lack adequate social support. 
The identification of these pathways may also aid in the development of targeted interventions aimed at preventing or ameliorating loneliness and increasing levels of social support.

\section{Method \\ Sample}

The study involved the participation of 624 community-dwelling participants attending the Technology Research for Independent Living (TRIL) clinic at St James's Hospital, Dublin. For a more comprehensive description of the TRIL clinic please refer to RomeroOrtuno, Cogan, Fan and Kenny (2010). Local Research Ethics Committee approval was obtained (SJH/AMNCH Research Ethics Committee approval reference number 2007/06/13). Of the 624 participants, 45 were excluded due to impaired cognition (Mini-Mental State Examination (MMSE) < 23) leaving a total of 579 participants. All participants gave their informed consent prior to their inclusion in the study.

\section{Primary measures}

De Jong-Gierveld scale for loneliness

Emotional and social loneliness were assessed using the six-item de Jong-Gierveld Loneliness Scale (de Jong Gierveld \& van Tilburg, 2006). In all, three items assessed emotional loneliness and three items assessed social loneliness. Both emotional and social loneliness are therefore given separate total scores from 0 to 3 , with increasing scores indicating increasing levels of loneliness.

\section{The Lubben Social Network Scale}

The 18-item Lubben Social Network Scale (LSNS-18; Lubben \& Gironda, 2004) examines perceived family, friendship and neighbourhood social support and, from this, gauges levels of social isolation. Individual scores for these aspects ranging from 0 to 30 are provided, as well as a total network score ranging from 0 to 90 . Higher scores indicate greater social support.

\section{Secondary measures}

A total of 82 measures from a battery of psychosocial, physiological, cognitive and demographic assessments and questionnaires were selected for inclusion in the initial bivariate comparisons with loneliness and social support (for a full list see Appendix 1, Table 1A). This initial screening process identified factors for inclusion in the multiple regression analyses and mediation analyses.

\section{Methods of analyses}

Data were analysed using SPSS 16.0. Spearman's Rank Correlation Coefficient was used to conduct bivariate correlations of selected psychosocial, biological, cognitive and demographic variables with scores of emotional loneliness, social loneliness and social support. Bonferroni adjusted levels were used to assess significance of the correlations. Variables found to be significantly correlated with one of these measures of loneliness or social network were then entered into separate (psychosocial, biological, cognitive and demographic) backward multiple linear regression analyses with the relevant measure (emotional loneliness, social loneliness and social support). Age and gender were included in all multiple regression analyses. Following this, the variables found to be significant risk factors in each model were collated and entered into a final multiple regression analysis with the relevant measure as the dependent variable (emotional loneliness, social loneliness and social support). Collinearity was assessed for all regression analyses and found not to be an issue. Supplementary analyses, utilising a bootstrapping approach was used to examine possible mediation effects of selected variables.

Path models demonstrating direct effects and indirect effects through a mediator are shown in Figure 1. A bootstrapping approach to mediation analyses has been recommended as one of the more valid and powerful methods currently available (Hayes, 2009; Shrout \& Bolger, 2002). Bootstrapping is a nonparametric resampling procedure, which makes no assumptions about the sampling distribution of the indirect effect. Bootstrapping involves the generation of a large number of datasets each of which is obtained through random sampling observations with replacement from the original dataset. The indirect effect is then calculated in each sample and results in the construction of a probability distribution from all of the resampled estimates. From these confidence intervals bootstrap-estimated standard errors of the mediated effects can be determined (Preacher \& Hayes, 2008; Shrout \& Bolger, 2002). Based on a SPSS macro (Preacher \& Hayes, 2008), this type of analysis was conducted to estimate bootstrap standard errors and bias-corrected confidence intervals (BC CI) around the mediated effect, based on $k=5000$ bootstrap samples. The significance level of $p<0.05$ was set for all regression and bootstrapping statistical procedures.

\section{Results \\ Bivariate correlations}

A total of 82 measures (for a full list see Appendix 1, Table 1A) were correlated in a bivariate analysis with scores of emotional loneliness, social loneliness and total social support network. Due to the large number of included measures a full list of the bivariate analysis results and the Bonferroni adjusted significance levels can be found in Appendix 1, Table 2A. 
(a)

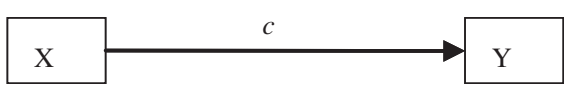

(b)

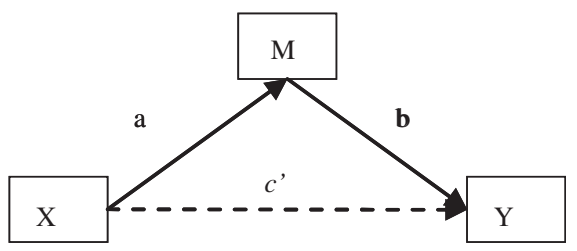

Figure 1. Path models showing (a) total effect and (b) mediated effect and direct effect. Mediation is indicated when the $\mathrm{c}^{\prime}$ path is smaller than the $\mathrm{c}$ path.

\section{Multiple linear regression analyses}

Variables significantly correlated with emotional loneliness, social loneliness or social support were entered into separate multiple regression psychosocial, biological, cognitive and demographic analyses. The emerging factors in each of these models were then entered into an overall multiple regression analyses with the relevant outcome.

\section{Emotional loneliness}

Using the backward method, a significant model emerged for emotional loneliness with respect to psychosocial variables $\left(F_{4,310}=41.995, \quad p<0.001\right)$, biological variables $\left(F_{2,444}=7.930, \quad p<0.001\right)$, cognitive variables $\left(F_{2,349}=7.337, p<0.01\right)$ and demographic variables $\left(F_{3,502}=12.151, \quad p<0.001\right)$. Following this, the significant risk factors of these models were combined and entered into a multiple linear regression with emotional loneliness as the dependent variable. A significant model emerged $\left(F_{6,268}=26.182, p<0.001\right)$ and accounted for $36.1 \%$ of the variance. Depression $(\beta=0.148, p<0.05)$, neuroticism $(\beta=0.302, p<0.001)$, perceived stress $(\beta=0.248, \quad p<0.001), \quad$ living alone $\quad(\beta=0.160$, $p<0.01)$ and type of accommodation $(\beta=0.116$, $p<0.05$ ) were significant risk factors in this model. The levels of significance of these models along with the risk factors in each model can be seen in Table 1 .

\section{Social loneliness}

With respect to psychosocial variables $\left(F_{2,315}=16.010\right.$, $p<0.001)$, cognitive variables $\left(F_{1,490}=9.075, p<\right.$ $0.01)$ and demographic variables $\left(F_{1,523}=12.903\right.$, $p<0.001$ ), significant models emerged for social loneliness. No biological model was computed as none of these variables reached significance in the preliminary correlation analyses following Bonferroni adjustment of the significance levels. When the significant risk factors of the models were combined and entered into a multiple regression analysis with social loneliness as the dependent variable, a significant model emerged $\left(F_{5,407}=12.388, p<0.001\right)$ and accounted for $12.3 \%$ of the variance. Neuroticism $(\beta=0.115, p<0.05)$, perceived stress $(\beta=0.232, p<0.001)$, verbal fluency as measured by animal naming $(\beta=0.167, p<0.01)$ and the number of alive grandchildren $(\beta=-0.134$, $p<0.01)$ were significant risk factors in this final overall model. The levels of significance and the risk factors of the categorised models as well as the final overall model can be seen in Table 2 .

\section{Social support network}

Significant multiple regression models emerged for social support with respect to psychosocial variables $\left(F_{6,382}=19.681, \quad p<0.001\right), \quad$ biological variables $\left(F_{6,368}=9.503, p<0.001\right)$, cognitive variables $\left(F_{2,131}=10.673, p<0.001\right)$ and demographic variables $\left(F_{4,498}=22.892, p<0.001\right)$. Following this, the significant risk factors of these models were combined and entered into a multiple linear regression with social support as the dependent variable. A significant model emerged $\left(F_{7.389}=16.299, p<0.001\right)$ and accounted for $21.6 \%$ of the variance. Extraversion $(\beta=0.260$, $p<0.001$ ), executive functioning as measured by the Trail Making Test (TMT) B time $(\beta=-0.157$, $p<0.01)$, history of falls $(\beta=-0.147, p<0.01)$, drives $(\beta=0.094, \quad p<0.05), \quad$ age $\quad(\beta=-0.136$, $p<0.01)$ and the Geriatric Adverse Life Events Scale (GALES) item 'difficulty getting access to adequate professional services' $(\beta=-0.100, p<0.05)$ were significant risk factors in this model. The levels of significance of these models along with the risk factors in each model can be seen in Table 3 .

\section{Supplementary mediation analyses}

Given the results of these multiple regression analyses, where final models of the strongest risk factors for emotional loneliness and social loneliness emerged, we conducted a mediation analysis to supplement the above analyses. Strong links between social support and loneliness have previously been found, however, the precise nature of these links is unclear. A bootstrapping approach to mediation analyses was used and due to the nature of this analysis no dichotomous variables could be included as potential mediators. Therefore, the current analysis aims to investigate whether any of the nondichotomous final items in the models for emotional and social loneliness mediate the effects of social support. That is, are there indirect effects of social support on emotional loneliness through depression, neuroticism, perceived stress or accommodation type? Additionally, are there indirect effects of social support on social loneliness through neuroticism, perceived stress, animal naming and the number of grandchildren an individual has? In these analyses, the independent variable was social support and the outcome variable was either emotional loneliness or social loneliness.

\section{Indirect effects of social support on emotional loneliness and social loneliness}

Path models conceptualising the results of the multiple mediation analyses can be seen in Figure 2. 
Table 1. The psychosocial, biological, cognitive, demographic and final overall multiple regression models for emotional loneliness.

\begin{tabular}{|c|c|c|c|c|c|}
\hline Model & $\beta$ & $p$ & $F$ & Model significance & $R^{2}$ adjusted \\
\hline Psychosocial & & & 41.995 & 0.000 & 0.346 \\
\hline Depression & 0.138 & 0.016 & & & \\
\hline Neuroticism & 0.247 & 0.000 & & & \\
\hline Perceived stress & 0.240 & 0.000 & & & \\
\hline Biological & & & 7.930 & 0.000 & 0.030 \\
\hline Pain & 0.121 & 0.016 & & & \\
\hline Berg Balance Scale & -0.106 & 0.034 & & & \\
\hline Cognitive & & & 7.337 & 0.004 & 0.035 \\
\hline CFQ & 0.147 & 0.006 & & & \\
\hline TMT A time & 0.133 & 0.012 & & & \\
\hline Demographic & & & 12.151 & 0.000 & 0.062 \\
\hline Lives alone & 0.163 & 0.000 & & & \\
\hline Type of Accommodation & 0.090 & 0.048 & & & \\
\hline Drives & -0.134 & 0.003 & & & \\
\hline Overall & & & 26.182 & 0.000 & 0.361 \\
\hline Depression & 0.148 & 0.015 & & & \\
\hline Neuroticism & 0.302 & 0.000 & & & \\
\hline Perceived stress & 0.248 & 0.000 & & & \\
\hline Lives alone & 0.160 & 0.002 & & & \\
\hline Type of accommodation & 0.116 & 0.025 & & & \\
\hline
\end{tabular}

Table 2. The psychosocial, biological, cognitive, demographic and final overall multiple regression models for social loneliness.

\begin{tabular}{|c|c|c|c|c|c|}
\hline Model & $\beta$ & $p$ & $F$ & Model significance & $R^{2}$ adjusted \\
\hline Psychosocial & & & 16.010 & 0.000 & 0.087 \\
\hline Neuroticism & 0.147 & 0.018 & & & \\
\hline Perceived stress & 0.203 & 0.001 & & & \\
\hline Cognitive & & & 9.075 & 0.003 & 0.016 \\
\hline Animal naming (verbal fluency) & 0.135 & 0.003 & & & \\
\hline Demographic & & & 12.903 & 0.000 & 0.022 \\
\hline Number of alive grandchildren & -0.155 & 0.000 & & & \\
\hline Overall & & & 12.388 & 0.000 & 0.123 \\
\hline Neuroticism & 0.115 & 0.028 & & & \\
\hline Perceived stress & 0.232 & 0.000 & & & \\
\hline Animal naming & 0.167 & 0.001 & & & \\
\hline Number of alive grandchildren & -0.134 & 0.006 & & & \\
\hline
\end{tabular}

Social support had significant total effects on both emotional loneliness $\left(B_{5,430}=-0.0115, p<0.01\right)$ and social loneliness $\left(B_{5,400}=-0.0222, p<0.001\right)$. As can be seen in Table 4 , an examination of the indirect effects indicates that a set depression, neuroticism, perceived stress and accommodation type do mediate the effect of social support on emotional loneliness. The difference between the total and direct effects is the total indirect effect through the four mediators. This total indirect effect has a point estimate of -0.0076 and a $95 \%$ BC bootstrap CI of -0.0122 to -0.0036 . An examination of the specific indirect effects indicates that there are significant indirect effects of social support on emotional loneliness through depression, perceived stress and accommodation type, since the $95 \%$ BC CIs do not contain zero for any of these mediators. Additionally, neuroticism was a marginally significant mediator as its 95\% BC CIs included zero at the upper limit.

For the output social loneliness, the total indirect effect through the four mediators is not significant indicating that a set perceived stress, neuroticism, animal naming and the number of grandchildren do not mediate the effect of social support on social loneliness (point estimate $=-0.0011, \quad 95 \% \mathrm{BC}$ CIs $=-0.0037$ to 0.0009 ). In comparison to emotional loneliness; an examination of the specific indirect effects of social support on social loneliness indicates that both neuroticism and perceived stress are marginally significant mediators as their BC CIs include zero at the upper limit. Animal naming and number of grandchildren do not contribute the indirect effect above and beyond perceived stress and neuroticism. 
Table 3. The psychosocial, biological, cognitive, demographic and final overall multiple regression models for social support.

\begin{tabular}{|c|c|c|c|c|c|}
\hline Model & $\beta$ & $p$ & $F$ & Model significance & $R^{2}$ adjusted \\
\hline $\begin{array}{l}\text { Psychosocial } \\
\text { Extraversion } \\
\text { Accident/injury } \\
\text { Age } \\
\text { Gender }\end{array}$ & $\begin{array}{r}0.299 \\
-0.097 \\
-0.228 \\
0.099\end{array}$ & $\begin{array}{l}0.000 \\
0.042 \\
0.000 \\
0.030\end{array}$ & 19.681 & 0.000 & 0.227 \\
\hline $\begin{array}{l}\text { Biological } \\
\text { ADL (self-rated) } \\
\text { History of falls } \\
\text { Pain } \\
\text { Age } \\
\text { Gender }\end{array}$ & $\begin{array}{r}0.127 \\
-0.133 \\
-0.102 \\
-0.172 \\
0.107\end{array}$ & $\begin{array}{l}0.013 \\
0.013 \\
0.045 \\
0.001 \\
0.038\end{array}$ & 9.503 & 0.000 & 0.120 \\
\hline $\begin{array}{l}\text { Cognitive } \\
\text { Trail Making Test B time } \\
\text { Age }\end{array}$ & $\begin{array}{l}-0.210 \\
-0.200\end{array}$ & $\begin{array}{l}0.025 \\
0.028\end{array}$ & 10.673 & 0.000 & 0.129 \\
\hline $\begin{array}{l}\text { Demographic } \\
\text { Voluntary work in the past year } \\
\text { Drives } \\
\text { Age }\end{array}$ & $\begin{array}{r}0.104 \\
0.195 \\
-0.258\end{array}$ & $\begin{array}{l}0.014 \\
0.000 \\
0.000\end{array}$ & 22.892 & 0.000 & 0.150 \\
\hline $\begin{array}{l}\text { Overall } \\
\text { Extraversion } \\
\text { History of falls } \\
\text { Trail Making Test B time } \\
\text { Drives } \\
\text { Age }\end{array}$ & $\begin{array}{r}0.260 \\
-0.147 \\
-0.157 \\
0.100 \\
-0.130\end{array}$ & $\begin{array}{l}0.000 \\
0.003 \\
0.002 \\
0.037 \\
0.010\end{array}$ & 16.299 & 0.000 & 0.216 \\
\hline
\end{tabular}

(a)

\begin{tabular}{|c|c|c|}
\hline $\begin{array}{c}\text { Social support } \\
\text { (LSNS-18) }\end{array}$ & $c=-0.0115^{* *}$ & $\begin{array}{c}\text { Emotional loneliness } \\
\text { (De Jong-Gierveld) }\end{array}$ \\
\cline { 2 - 3 }
\end{tabular}

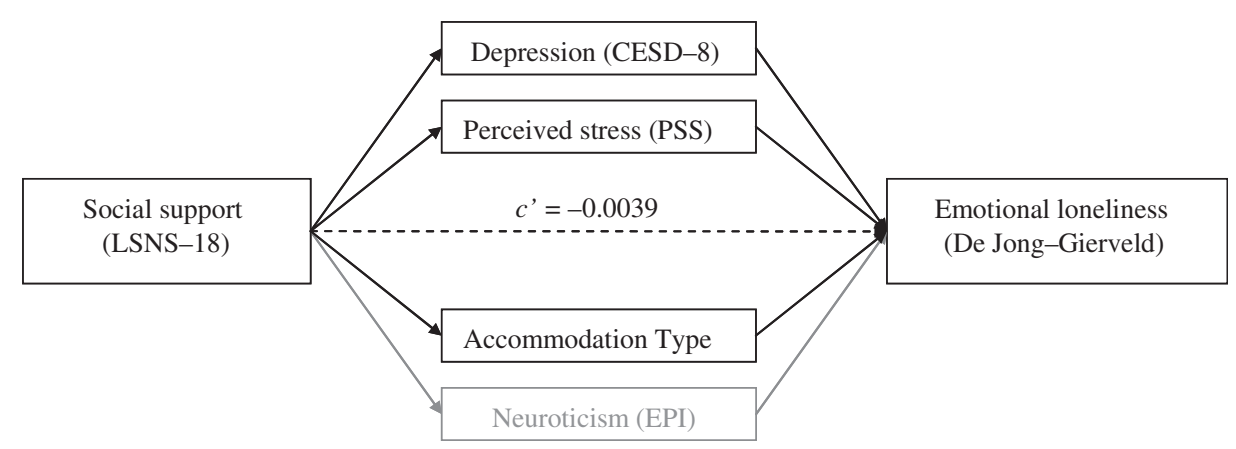

(b)
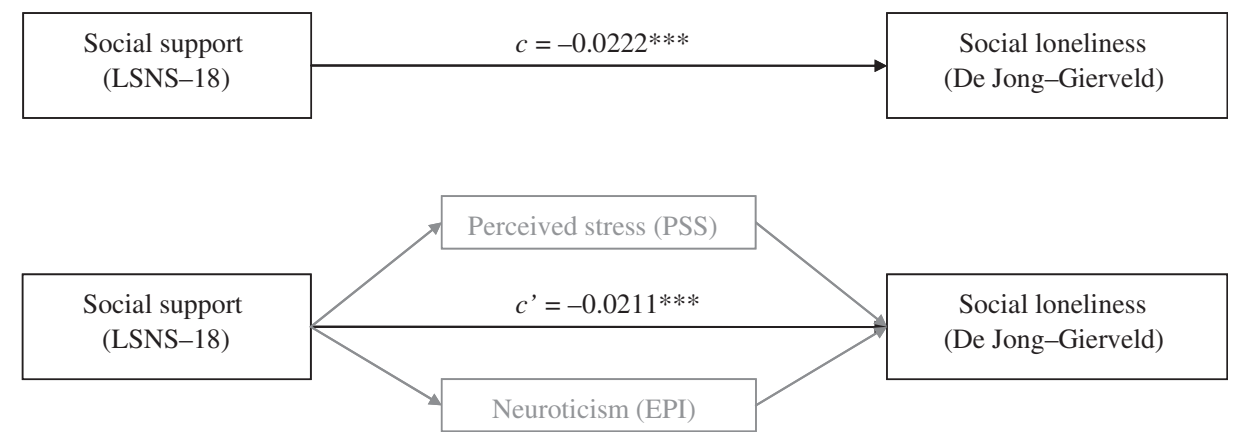

Figure 2. Conceptual diagram showing the multiple mediation models for total, direct and indirect effects of social support on (a) emotional loneliness and (b) social loneliness. Marginally significant mediators are indicated by greyscale. Significance levels: $* * * p<0.001, * * p<0.01$. 
Table 4. Point estimates, standard error, $z$-values and $95 \%$ bias-corrected confidence intervals for indirect effects of social support on emotional loneliness and social loneliness.

\begin{tabular}{|c|c|c|c|c|c|c|}
\hline & \multirow{2}{*}{$\begin{array}{l}\text { Indirect } \\
\text { effects }\end{array}$} & \multirow{2}{*}{$\begin{array}{l}\text { Point } \\
\text { estimate }\end{array}$} & \multicolumn{2}{|c|}{ Product of coefficients } & \multicolumn{2}{|c|}{ Bootstrap $95 \% \mathrm{BC}^{\mathrm{a}} \mathrm{CI}$} \\
\hline & & & SE & $z$ & Lower & Upper \\
\hline \multirow[t]{5}{*}{ Emotional loneliness $(N=436)$} & Total & -0.0076 & 0.0021 & -3.6797 & -0.0122 & -0.0036 \\
\hline & Depression & -0.0024 & 0.0009 & -2.6322 & -0.0049 & -0.0008 \\
\hline & Neuroticism & -0.0017 & 0.0010 & -1.7543 & -0.0042 & 0.0000 \\
\hline & Perceived stress & -0.0023 & 0.0010 & -2.4317 & -0.0050 & -0.0007 \\
\hline & Type of accommodation & -0.0011 & 0.0006 & -1.1508 & -0.0027 & -0.0001 \\
\hline \multirow[t]{5}{*}{ Social loneliness $(N=406)$} & Total & -0.0011 & 0.0011 & -1.0435 & -0.0037 & 0.0009 \\
\hline & Perceived stress & -0.0012 & 0.0007 & -1.7187 & -0.0033 & 0.0000 \\
\hline & Neuroticism & -0.0005 & 0.0004 & -1.2671 & -0.0018 & 0.0000 \\
\hline & Animal naming & 0.0002 & 0.0005 & 0.5024 & -0.0006 & 0.0015 \\
\hline & $\begin{array}{l}\text { Number of alive } \\
\text { grandchildren }\end{array}$ & 0.0003 & 0.0004 & 0.8021 & -0.0004 & 0.0014 \\
\hline
\end{tabular}

Notes: ${ }^{\mathrm{a}} \mathrm{BC}=$ bias-corrected; 5000 bootstrap samples.

Significance at $<.05$ (if confidence intervals do not cross zero, then the relationship is significant).

\section{Discussion}

The current study identified comprehensive models of emotional loneliness, social loneliness and social support from an exploration of a range of biopsychosocial, cognitive and demographic assessments in a sample of community-dwelling older adults in Ireland. The differing nature of these models confirms the importance of distinguishing between different types of loneliness and also between a lack of social support and loneliness. Additionally, a representation of the direct and indirect effects of social support on emotional and social loneliness through their identified risk factors has been constructed. Social support was found to affect emotional loneliness indirectly through several factors. In contrast, the effect of social support on social loneliness was primarily direct. This has important implications in the development of interventions targeting loneliness.

\section{Multiple regression analyses}

According to the overall multiple regression model constructed following individual psychosocial, biological, cognitive and demographic analyses, the psychosocial variables were the most likely to appear in the final model for emotional loneliness with no cognitive or biological variables emerging. Higher levels of neuroticism, depression and perceived stress were all significant indicators of increased emotional loneliness, as was living alone and the type of accommodation lived in. Risk factors of social loneliness are slightly more varied. Both neuroticism and perceived stress are still found to be important in the overall model, however, animal naming, a measure of semantic fluency, is also found to be a risk factor. Additionally, the number of grandchildren an individual has also appears in the final model for social loneliness, with individuals with fewer grandchildren being more likely to be socially lonely.
The final model for social support is entirely different from those for the different forms of loneliness. Lower levels of extraversion was the strongest indicator of decreased social support although higher scores on the TMT B time, indicating greater impairment in executive functioning, and having a history of falling were also strong indicators. Other risk factors for lower levels of social support included increasing age and not being able to drive.

The differing models for emotional loneliness, social loneliness and social support confirm the usefulness of distinguishing between these outcomes. The predominance of mood and personality factors in both loneliness models indicates that they do share some similar characteristics and confirms previous research in these areas (Barg et al., 2006; Cacioppo et al., 2006; Fees et al., 1999; Lasgaard \& Elklit, 2009; Savikko, 2008; Stek et al., 2005; Stokes, 1985). Living arrangements, principally living alone, were identified as particularly important for emotional loneliness inline with Weiss' (1973) original definition involving the lack or loss of a close attachment relationship. Interestingly, social support was the only outcome in which a biological variable, falls history, emerged in the final model; this may indicate the relative importance of health factors compared to psychosocial factors in the loneliness models. The presence of a cognitive variable in both of the overall models for social loneliness and social support, but not emotional loneliness, reflects the relative importance of cognition to each of these outcomes and may be a sign of the importance of cognition to engaging in social activities and in instigating and maintaining social relationships. Specifically, animal naming, a measure of semantic fluency, was identified as a major indicator of social loneliness in the current analysis and this corresponds with previous research by Gilmour (2011) identifying a relationship between low levels of semantic fluency and general loneliness. It is possible that deficits in semantic fluency may discourage conversations with friends and 
family leading to an increased perception of loneliness. In contrast, social support was indicated by the TMT B time, a measure of executive functioning, which relates to previous findings identifying a limited social network as increasing risk of dementia by $60 \%$ (Fratiglioni et al., 2000). Difficulties in the maintenance of social networks may be a key issue here.

\section{Mediation analyses}

A secondary aim was to investigate mediating effects in the relationship between social support and the outcomes of emotional and social loneliness. Strong links between levels of social support and loneliness are evident. Social support was identified as a risk factor of both emotional loneliness and social loneliness; however, distinct models for these relationships emerge once potential mediators are considered. Interestingly, the significant effect of social support on emotional loneliness no longer reached significance following the addition of the mediators; that is, the total effect (c path) was much greater than the direct effect ( $c^{\prime}$ path). This indicates a large proportion of the effect of social support on emotional loneliness is not direct but is instead indirect through depression, perceived stress and living arrangements, although marginal effects through neuroticism were also indicated.

In comparison, little change occurred in the effect of social support on social loneliness following the inclusion of potential mediators; both the total effect (c path) and the direct effect ( $c^{\prime}$ path) of social support on social loneliness were significant. This is in stark contrast to the effect of social support on emotional loneliness. The effects of smaller levels of social support on feelings of social loneliness were almost entirely direct in nature; although marginally significant indirect effects did occur through increasing levels of perceived stress and neuroticism.

These results highlight the differences in the manner by which social support influences the levels of emotional loneliness and social loneliness. Social support predominantly affects emotional loneliness indirectly, while its effects on social loneliness are nearly exclusively direct. Interventions aimed at targeting loneliness should therefore tailor their approach depending on the type of loneliness present. Our findings suggest that interventions targeting depression, perceived stress, living arrangements and neuroticism may be valuable in buffering the relationship between social support and emotional loneliness. In contrast, directly targeting social support may be the most effective method of ameliorating feelings of social loneliness, although interventions aimed at perceived stress and neuroticism may also be beneficial in buffering this relationship.

\section{Methodological issues and future research}

An array of standardised and validated biopsychosocial assessments were employed in the current study. It is hoped this inclusion of a broad range of assessments allowed for a more accurate and in-depth appraisal of the risk factors of emotional loneliness, social loneliness and social support. However, the possibility that our initial broad approach has led to false positive findings should be considered. It is hoped that the conservative nature of the analysis, utilising Bonferroni corrected significance levels at the screening stage followed by conservative backwards linear regression analyses has helped to reduce this possibility. It should also be considered that this methodological approach was overly conservative, resulting in very few variables in the final overall models.

The cross-sectional nature of the study limits the degree to which we can interpret direct and indirect causality with regard to loneliness and social support. This issue is to be addressed in a longitudinal follow-up of participants currently taking place at the TRIL clinic. Additionally, all participants in the current study were community-dwelling adults in Ireland, aged over 60 and therefore the resulting models of emotional loneliness, social loneliness and social support, as well as the indirect effects discussed previously are specific to this population and may not be generalised to other populations. It is likely that these individuals are better functioning than people in support living environments and this should be taken into account when considering the results. Additionally, there may be cultural differences in the development of loneliness and social support. Future research will focus on a more comprehensive investigation of indirect effects with regard to biopsychosocial factors and emotional and social loneliness.

An important aspect of loneliness not considered in the current analysis is an exploration of the risk factors of being both emotionally and socially lonely. The current analysis focused on emotional and social loneliness as separate entities. However, it is possible to be both socially and emotionally lonely and therefore modelling the simultaneous occurrence of these two types of loneliness is of clinical significance. Additionally, the possibility of additive and superadditive effects exists and is needful for investigation, when both emotional and social loneliness are present.

The analyses of the indirect pathways by which social support can affect loneliness were based on the primary risk factors identified. A more comprehensive investigation of these pathways could have included a large number of other potential mediators based on the earlier individual demographic, psychosocial, cognitive and biological risk factor models developed. Such a complex and extensive analyses may be better examined through a process such as structural equation modelling and is a topic which should be considered for future research.

In conclusion, the present study identified the main risk factors of developing emotional loneliness, social loneliness or a decreased perception of available social support. It also determined both the direct and indirect pathways by which social support can affect loneliness. 
These findings are of crucial importance in the development of a broader representation of who is vulnerable to becoming lonely and why. Interventions aimed at preventing or ameliorating loneliness should tailor their approaches depending on the nature and the direction of these direct and indirect pathways.

\section{Acknowledgements}

This research was completed as part of a wider programme of research within the TRIL (Technology Research for Independent Living) Centre.

\section{References}

Barg, F., Huss-Ashmore, R., Wittink, M., Murray, G., Bogner, H., \& Gallo, J. (2006). A mixed-methods approach to understanding loneliness and depression in older adults. Journal of Gerontology: Social Sciences, 61B, 329-339.

Cacioppo, J.T., Fowler, J.H., \& Christakis, N.A. (2009). Alone in the crowd: The structure and spread of loneliness in a large social network. Journal of Personality and Social Psychology, 97, 977-991.

Cacioppo, J.T., Hawkley, L.C., Crawford, E., Ernst, J.M., Burleson, M.H., Kowalewski, R.B., \& ,..., Berntson, G.G. (2002). Loneliness and health: Potential mechanisms. Psychosomatic Medicine, 64, 407-417.

Cacioppo, J.T., Hughes, M.E., Waite, L.J., Hawkley, L.C., \& Thisted, T. (2006). Loneliness as a specific risk factor for depressive symptoms in older adults: Cross-sectional and longitudinal analyses. Psychology and Aging, 21, $140-151$.

De Jong Gierveld, J., \& van Tilburg, T. (2006). A 6-item scale for overall, emotional, and social loneliness; confirmatory tests on survey data. Research on Aging, $28,582-598$.

De Jong Gierveld, J., van Tilburg, T., \& Dykstra, P.A. (2006). Loneliness and social isolation. In A. Vangelisti \& D. Perlman (Eds.), Cambridge handbook of personal relationships (pp. 485-500). Cambridge: Cambridge University Press.

Drennan, J., Treacy, M., Butler, M., Byrne, A., Fealy, G., Frazer, K., \& Irving, K. (2008). The experience of social and emotional loneliness among older people in Ireland. Ageing and Society, 28, 1113-1132.

Fees, B.S., Martin, P., \& Poon, L.W. (1999). A model of loneliness in older adults. Journal of Gerontology: Psychological Sciences, 54B, 231-239.

Fratiglioni, L., Wang, H.X., Ericsson, K., Maytan, M., \& Winblad, B. (2000). Influence of social network on occurrence of dementia: A community-based longitudinal study. Lancet, 355, 1315-1319.

Gilmour, H. (2011). Cognitive performance of Canadian seniors. Health Reports, 22, 1-5.

Golden, J., Conroy, R.M., Bruce, I., Denihan, A., Greene, E., Kirby, M., \& Lawlor, B.A. (2009). Loneliness, social supports, mood and wellbeing in community-dwelling elderly. International Journal of Geriatric Psychiatry, 24, 694-700.

Gurung, R.A.R., Taylor, S.E., \& Seeman, T.E. (2003). Accounting for changes in social support among married older adults: Insights from the MacArthur Studies of Successful Aging. Psychology and Aging, 18, 487.
Hayes, A.F. (2009). Beyond Baron and Kenny: Statistical mediation analysis in the new millennium. Communication Monographs, 76, 408-420.

Hawkley, L.C., Masi, C.M., Berry, J.D., \& Cacioppo, J.T. (2006). Loneliness is a unique predictor of age-related differences in systolic blood pressure. Psychology and Aging, 21, 52-164.

Heylen, L. (2010). The older, the lonelier? Risk factors for social loneliness in old age. Ageing \& Society, 30, $1177-1196$.

Kramer, S.E., Kapteyn, T.S., Kuik, D.J., \& Deeg, D.J.H. (2002). The association of hearing impairment and chronic diseases with psychosocial health status in older age. Journal of Aging and Health, 14, 122-137.

Lansford, J.E., Sherman, A.M., \& Antonucci, T.C. (1998). Satisfaction with social networks: An examination of socioemotional selectivity theory across cohorts. Psychology and Aging, 13, 544.

Lasgaard, M., \& Elklit, A. (2009). Prototypic features of loneliness in a stratified sample of adolescents. Interpersona, 3, 85-110.

Lauder, W., Mummery, K., Jones, M., \& Caperchione, C. (2006). A comparison of health behaviours in lonely and non-lonely populations. Psychology, Health \& Medicine, 11, 233-245.

Long, M.V., \& Martin, P. (2000). Personality, relationship closeness and loneliness of the oldest old and their children. The Journals of Gerontology: Psychological Sciences, 55B, 311-319.

Lubben, J., \& Gironda, M. (2004). Measuring social networks and assessing their benefits. In C. Phillipson, G. Allan, \& D. Morgan (Eds.), Social networks and social exclusion: Sociological and policy perspectives (pp. 20-35). Hampshire, UK: Ashgate.

Patterson, A.C., \& Veenstra, G. (2010). Loneliness and risk of mortality: A longitudinal investigation in Alameda County, California. Social Science \& Medicine, 71, 181-186.

Penninx, B.W., van Tilburg, T., Kriegsman, D.M., Boeke, A.J., Deeg, D.J., \& van Eijk, J.T. (1999). Social network, social support, and loneliness in older persons with different chronic diseases. Journal of Aging and Health, 11, 151-168.

Perlman, D., \& Peplau, L.A. (1981). Toward a social psychology of loneliness. In R. Gilmour \& S. Duck (Eds.), Personal relationships: Personal relations in disorder (pp. 31-56). London: Academic Press.

Preacher, K.J., \& Hayes, A.F. (2008). Asymptotic and resampling strategies for assessing and comparing indirect effects in multiple mediator models. Behavior Research Methods, 40, 879-891.

Romero-Ortuno, R., Cogan, L., Fan, C.W., \& Kenny, R.A. (2010). Intolerance to initial orthostasis relates to systolic BP changes in elders. Clinical Autonomic Research, 20, 39-45.

Routasalo, P., Savikko, N., Tilvis, R.S., Strandberg, T.E., \& Pitkälä Kaisu, H. (2006). Social contacts and their relationship to loneliness among aged people - A population-based study. Gerontology, 52, 181-187.

Russell, D.W., \& Cutrona, C.E. (1991). Social support, stress, and depressive symptoms among the elderly: Test of a process model. Psychology and Aging, 6, 190.

Savikko, N. (2008). Loneliness of older people and elements of an intervention for its alleviation (Doctoral dissertation). Annales Universitatis Turkuensis.

Shrout, P.E., \& Bolger, N. (2002). Mediation in experimental and nonexperimental studies: New 
procedures and recommendations. Psychological Methods, 7, 422-445.

Sorkin, D., Rook, K.S., \& Lu, J.L. (2002). Loneliness, lack of emotional support, lack of companionship and the likelihood of having a heart condition in an elderly sample. Annual Behavioural Medicine, 24, 290-298.

Stek, M.L., Vinkers, D.J., Gussekloo, J., van der Mast, R.C., Beekman, A.T., \& Westendorp, R.G. (2005). Is depression in old age fatal only when people feel lonely? American Journal of Psychiatry, 162, 178-180.

Steptoe, A., Owen, N., Kunz-Ebrecht, S.R., \& Brydon, L. (2004). Loneliness and neuroendocrine, cardiovascular, and inflammatory stress responses in middle-aged men and women. Psychoneuroendocrinology, 29, 593-611.

Stokes, J.P. (1985). The relation of social network and individual difference variables to loneliness. Journal of Personality and Social Psychology, 48, 981-990.
Tilvis, R.S., Kahonen-Vare, M.H., Jolkkonen, J., Valvanne, J., Pitkala, K.H., \& Strandberg, T.E. (2004). Predictors of cognitive decline and mortality of aged people over a 10-year period. Journals of Gerontology Series A: biological Sciences and Medical Sciences, 59, 268-274.

van Baarsen, B., Snijders, T.A.B., Smit, J.H., \& van Duijn, M.A.J. (2001). Lonely but not alone: Emotional isolation and social isolation as two distinct dimensions of loneliness in older people. Educational and Psychological Measurement, 61, 119-135.

Weiss, R.S. (1973). The experience of emotional and social isolation. Cambridge: MIT Press.

Wilson, R.S., Krueger, K.R., Arnold, S.E., Schneider, J.A., Kelly, J.F., Barnes, L.L., \& Bennett, D.A. (2007). Loneliness and risk of Alzheimer disease. Archives of General Psychiatry, 64, 234-240.

\section{Appendix 1}

Table 1A. The psychosocial, biological, cognitive and demographic variables for inclusion in the bivariate Spearman's Rank Correlation Coefficient analyses with emotional loneliness, social loneliness and social support.

\begin{tabular}{|c|c|c|c|}
\hline \multicolumn{4}{|c|}{ Variables for inclusion } \\
\hline Psychosocial & $\begin{array}{l}\text { CESD-7 (depression) } \\
\text { HADS (anxiety) } \\
\text { Pittsburg sleep index } \\
\quad \text { (perceived sleep quality) } \\
\text { Neuroticism } \\
\text { Extraversion } \\
\text { Perceived Stress Scale } \\
\text { Modified falls efficacy scale } \\
\text { GALES items: } \\
\text { Financial difficulties } \\
\text { Retirement } \\
\text { Sudden loss of employment } \\
\text { New major physical illness } \\
\text { Other major physical illness } \\
\text { Physical illness of close } \\
\text { family member }\end{array}$ & $\begin{array}{l}\text { GALES items continued: } \\
\text { Accident/injury } \\
\text { Marital separation/divorce } \\
\text { Other marital difficulties } \\
\text { Major family problems other } \\
\text { than with spouse } \\
\text { Major problems with friends/ } \\
\text { neighbours } \\
\text { Break-up of a long-term } \\
\text { relationship (not marriage) } \\
\text { Separation from other close } \\
\text { friend/relative } \\
\text { Death of spouse } \\
\text { Death of child } \\
\text { Death of parent } \\
\text { Death of a brother/sister }\end{array}$ & $\begin{array}{l}\text { GALES items continued: } \\
\text { Death of other relative/close friend } \\
\text { Death of a pet } \\
\text { Forced to leave/lose home } \\
\text { Voluntarily changed place of residence } \\
\text { Individual moved out of household } \\
\text { Individual moved into household } \\
\text { Difficulty getting adequate } \\
\text { professional services } \\
\text { Victim of crime } \\
\text { Became caretaker for relative/friend }\end{array}$ \\
\hline Biological & $\begin{array}{l}\text { Fried Frailty Index } \\
\text { Timed get up and go } \\
\quad \text { (walking speed) } \\
\text { Berg Balance Scale } \\
\text { Charlson Comorbidity Index } \\
\text { Falls hstory } \\
\text { MNA (nutrition) }\end{array}$ & $\begin{array}{l}\text { Visual acuity } \\
\text { Hearing test } \\
\text { Activities of daily living } \\
\text { (self-rated physical functioning) } \\
\text { Instrumental activities of daily } \\
\text { living (self-rated physical } \\
\text { functioning) }\end{array}$ & $\begin{array}{l}\text { Pain score } \\
\text { Baseline systolic blood pressure } \\
\text { Nadir systolic blood pressure } \\
\text { Delta systolic blood pressure } \\
\text { Recoverer type (blood pressure) } \\
\text { Maximum systolic blood pressure }\end{array}$ \\
\hline Cognitive & $\begin{array}{l}\text { MMSE } \\
\text { Cognitive Failures } \\
\text { Questionnaire } \\
\text { Prospective memory: } \\
\text { hidden belongings } \\
\text { Prospective memory: } \\
\text { questions } \\
\text { Initial word recall } \\
\text { Delayed word recall }\end{array}$ & $\begin{array}{l}\text { Animal naming (verbal fluency) } \\
\text { Digit span backwards } \\
\text { Intelligence quotient - cognition } \\
\text { CAMCOG: recognition } \\
\text { CAMCOG: similarities } \\
\text { CAMCOG: draw }\end{array}$ & $\begin{array}{l}\text { CAMCOG: recall } \\
\text { CAMCOG: naming } \\
\text { TMT A time (sec) } \\
\text { TMT B time (sec) } \\
\text { TMT B minus A } \\
\text { Praxis }\end{array}$ \\
\hline Demographic & $\begin{array}{l}\text { Marital status } \\
\text { Educational level } \\
\text { Working status } \\
\text { Voluntary work in the } \\
\quad \text { past year }\end{array}$ & $\begin{array}{l}\text { Childless } \\
\text { Number of alive children } \\
\text { Number of alive grandchildren } \\
\text { Type of accommodation }\end{array}$ & $\begin{array}{l}\text { Lives alone } \\
\text { Drives } \\
\text { Urban vs. rural }\end{array}$ \\
\hline
\end{tabular}


Table 2A. Bivariate Spearman's Rank Correlation Coefficient comparisons of emotional loneliness, social loneliness and social support scores with 82 psychosocial, cognitive, physiological and demographic variables.

\begin{tabular}{|c|c|c|c|c|}
\hline & Variable & $\begin{array}{l}\text { Emotional } \\
\text { loneliness }\end{array}$ & $\begin{array}{c}\text { Social } \\
\text { loneliness }\end{array}$ & $\begin{array}{c}\text { Social } \\
\text { support }\end{array}$ \\
\hline Psychosocial & $\begin{array}{l}\text { Depression (CESD-7) } \\
\text { Anxiety (HADS-A) } \\
\text { Pittsburgh sleep index } \\
\text { Neuroticism } \\
\text { Extraversion } \\
\text { Perceived Stress Scale } \\
\text { Modified falls efficacy scale } \\
\text { GALES items } \\
\text { Financial difficulties } \\
\text { Retirement } \\
\text { Sudden loss of employment } \\
\text { New major physical illness } \\
\text { Other major physical illness } \\
\text { Physical illness of close family member } \\
\text { Accident/injury } \\
\text { Marital separation/divorce } \\
\text { Other marital difficulties } \\
\text { Major family problems other than with spouse } \\
\text { Major problems with friends/neighbours } \\
\text { Break-up of a long-term relationship other than marriage } \\
\text { Separation from other close friend/relative } \\
\text { Death of spouse } \\
\text { Death of child } \\
\text { Death of parent } \\
\text { Death of a brother/sister } \\
\text { Death of other relative/close friend } \\
\text { Death of a pet } \\
\text { Forced to leave/lose home } \\
\text { Voluntarily changed place of residence } \\
\text { Individual moved out of household } \\
\text { Individual moved into household } \\
\text { Difficulty getting adequate professional services } \\
\text { Victim of crime } \\
\text { Became caretaker for relative/friend }\end{array}$ & $\begin{array}{c}0.374^{*} \\
0.429^{*} \\
0.184^{*} \\
0.427 * \\
0.033 \\
0.415^{*} \\
-0.200^{*} \\
\\
0.017 \\
0.031 \\
0.033 \\
-0.006 \\
0.122 \\
0.089 \\
0.074 \\
0.073 \\
0.086 \\
0.040 \\
0.079 \\
0.062 \\
0.104 \\
0.080 \\
0.052 \\
0.072 \\
0.012 \\
-0.029 \\
-0.036 \\
0.003 \\
0.058 \\
-0.024 \\
-0.122 \\
0.137 \\
0.025 \\
0.093\end{array}$ & $\begin{array}{r}0.165^{*} \\
0.194^{*} \\
0.103 \\
0.186^{*} \\
-0.136 \\
0.180^{*} \\
-0.161^{*} \\
\\
0.090 \\
0.018 \\
-0.011 \\
0.005 \\
-0.008 \\
-0.050 \\
0.031 \\
0.021 \\
0.052 \\
0.107 \\
0.019 \\
0.049 \\
0.039 \\
-0.065 \\
-0.043 \\
-0.022 \\
-0.023 \\
-0.019 \\
-0.016 \\
0.014 \\
0.048 \\
0.007 \\
-0.057 \\
0.078 \\
-0.036 \\
0.004\end{array}$ & $\begin{array}{r}0.018 \\
-0.008 \\
0.062 \\
-0.030 \\
-0.079 \\
0.103 \\
-0.188^{*} \\
-0.061 \\
-0.039 \\
-0.035 \\
-0.060 \\
-0.053 \\
0.017 \\
0.033 \\
0.061 \\
0.032 \\
0.022 \\
0.059 \\
0.049 \\
-0.010 \\
0.012 \\
-0.034 \\
0.085 \\
-0.091 \\
-0.035 \\
0.050\end{array}$ \\
\hline Biological & $\begin{array}{l}\text { Timed get up and go } \\
\text { Fried Frailty Index } \\
\text { Berg Balance Score } \\
\text { Activities of daily living (self-rated) } \\
\text { Instrumental activities of daily living (self-rated) } \\
\text { Charlson Comorbidity Index } \\
\text { History of falls } \\
\text { MNA (nutrition) } \\
\text { Pain score (VRS) } \\
\text { Visual acuity - binocular } \\
\text { Hearing test } \\
\text { Baseline SBP } \\
\text { Maximum SBP } \\
\text { Nadir SBP } \\
\text { Delta SBP } \\
\text { Type of recoverer (fast or slow) }\end{array}$ & $\begin{array}{l}0.207^{*} \\
0.153^{*} \\
-0.248^{*} \\
-0.130^{*} \\
-0.179^{*} \\
0.094 \\
0.134^{*} \\
0.133^{*} \\
0.170^{*} \\
0.119 \\
0.122 \\
-0.069 \\
-0.043 \\
-0.016 \\
-0.071 \\
-0.073\end{array}$ & $\begin{array}{r}0.017 \\
-0.012 \\
-0.059 \\
-0.071 \\
-0.072 \\
0.051 \\
0.090 \\
0.080 \\
0.087 \\
0.032 \\
0.004 \\
-0.026 \\
0.002 \\
0.005 \\
-0.045 \\
-0.064\end{array}$ & $\begin{array}{r}-0.325^{*} \\
-0.195^{*} \\
0.310^{*} \\
0.149^{*} \\
0.296^{*} \\
-0.219^{*} \\
-0.247^{*} \\
-0.160^{*} \\
-0.173^{*} \\
-0.147^{*} \\
-0.193^{*} \\
-0.053 \\
-0.057 \\
-0.020 \\
-0.041 \\
-0.048\end{array}$ \\
\hline Cognitive & $\begin{array}{l}\text { Word recall initial } \\
\text { Delayed word recall } \\
\text { Animal naming (verbal fluency) } \\
\text { Digit backwards } \\
\text { Camcog similarities } \\
\text { Prospective memory: hidden belongings } \\
\text { Prospective memory: questions } \\
\text { TMT A time (sec) } \\
\text { TMT B time (sec) } \\
\text { TMT B minus A } \\
\text { CAMCOG: naming } \\
\text { CAMCOG: draw } \\
\text { CAMCOG: recall }\end{array}$ & $\begin{array}{r}-0.024 \\
-0.098 \\
-0.015 \\
-0.062 \\
-0.106 \\
-0.076 \\
-0.124 \\
0.148^{*} \\
0.119 \\
0.081 \\
-0.008 \\
-0.070 \\
0.016\end{array}$ & $\begin{array}{r}0.058 \\
0.040 \\
0.137^{*} \\
0.046 \\
0.056 \\
0.079 \\
-0.021 \\
-0.047 \\
-0.002 \\
0.025 \\
-0.056 \\
-0.036 \\
-0.092\end{array}$ & $\begin{array}{l}0.260^{*} \\
0.219^{*} \\
0.033 \\
0.152^{*} \\
0.119 \\
0.210^{*} \\
0.152 \\
-0.207^{*} \\
-0.287^{*} \\
-0.281^{*} \\
0.072 \\
0.191^{*} \\
0.187\end{array}$ \\
\hline
\end{tabular}


Table 2A. Continued.

\begin{tabular}{|c|c|c|c|c|}
\hline & Variable & $\begin{array}{l}\text { Emotional } \\
\text { loneliness }\end{array}$ & $\begin{array}{c}\text { Social } \\
\text { loneliness }\end{array}$ & $\begin{array}{c}\text { Social } \\
\text { support }\end{array}$ \\
\hline & CAMCOG: recognition & -0.037 & -0.014 & 0.055 \\
\hline & Praxis & -0.090 & -0.034 & $0.143 *$ \\
\hline & Intelligence quotient - cognition & -0.080 & 0.033 & 0.059 \\
\hline & Cognitive Failures Questionnaire Score & $0.185^{*}$ & 0.026 & $-0.155^{*}$ \\
\hline & MMSE score & -0.085 & -0.005 & $0.203^{*}$ \\
\hline \multirow[t]{13}{*}{ Demographic } & Marital status & 0.087 & 0.013 & -0.062 \\
\hline & Educational level & -0.080 & 0.061 & $0.137 *$ \\
\hline & Working status & -0.041 & 0.017 & 0.099 \\
\hline & Voluntary work in the past year & 0.006 & -0.025 & $0.162 *$ \\
\hline & Childless & 0.007 & 0.063 & -0.102 \\
\hline & Number of alive children & -0.022 & -0.099 & 0.099 \\
\hline & Number of alive grandchildren & 0.028 & $-0.165^{*}$ & 0.046 \\
\hline & Lives alone & $0.181^{*}$ & 0.109 & -0.106 \\
\hline & Drives & $-0.146^{*}$ & -0.046 & $0.248 *$ \\
\hline & Type of accommodation & $0.134^{*}$ & 0.084 & -0.126 \\
\hline & Urban vs. rural living & -0.058 & -0.093 & -0.007 \\
\hline & Age & 0.068 & -0.017 & $-0.283^{*}$ \\
\hline & Gender & 0.089 & 0.007 & 0.033 \\
\hline
\end{tabular}

Note: *Bonferroni adjusted significance levels: psychosocial, $p<0.001389$; biological, $p<0.002632$; cognitive, $p<0.002381$ and demographic, $p<0.003125$. 